Original Article

\title{
THE INFLUENCE OF THE SAGITTAL DENTOSKELETAL PATTERN ON THE VALUE OF THE SOFT TISSUE PROFILE ANGLES - A CEPHALOMETRIC STUDY
}

\author{
Tatjana Perovici ${ }^{1,2}$, Milena Blažej ${ }^{3}$, Ivan Jovanović ${ }^{1}$ \\ ${ }^{1}$ Faculty of Medicine, University of Niš, Niš, Serbia \\ ${ }^{2}$ Dental Clinic, Department for Orthodontics, Niš, Serbia \\ ${ }^{3}$ Private dental clinic, Smiledent, Niš, Serbia
}

\begin{abstract}
The aim of this study has been to establish the values of soft tissue profile angles in subjects with dentoskeletal Class I, Class II Division 1, Class II Division 2, and Class III pattern, in order to examine the influence of sagittal dentoskeletal relation on the value of angular profile parameters. This comparative cephalometric study included the examination and the analysis by lateral cephalograms to evaluate soft tissue profile angles for 120 adult Caucasian subjects (60 women and 60 men) from the mid Balkan region divided into four groups towards ANB angle and incisors inclination. The following angles were examined: angle of facial convexity, facial convexity angle for the lower face and the angle of total facial convexity. By investigating the influence of the sagittal dentoskeletal pattern on the value of facial convexity angles, significant differences have been established between subjects with Class I and Class II Division 1 and 2 for all examined angles ( $<0.001 ; p=0.011)$, while the differences between Class I and Class III are only significant for the facial convexity angle and facial convexity angle for the lower face, while the differences in the overall facial convexity angle are not significant $(p=0.067)$. There are significant differences between subjects for all examined angles except the total facial convexity angle between Class I and Class III.
\end{abstract}

Key words: cephalometry, face, malocclusions.

\section{Introduction}

The human face profile represents the perspective of a person's face at an angle of $90^{\circ}$ in relation to the "en face" projection. It can be viewed from the aspect of aesthetics and the aspect of harmony. The aesthetic aspect is very important because the human face plays a key role in basic social interactions. Therefore, it is no surprise that people with pleasant faces are considered socially more successful in life. When assessing facial beauty, psychological effects and personal attitudes are superimposed $[1,2]$. Profile harmony, unlike aesthetics, is defined by numerous parameters (among them the angle ones are predominant), making it clearly defined and measurable. Angle thought that universal measurement for assessing different facial profiles harmony [3] cannot be applied, because the profile morphotype is affected by various factors such as: ethnic and geographical [4], gender [5], ecological, biological, age and nutritional factors [6]

On the other hand, the profile aesthetics is the ultimate result of some other factors that are not related only to the profile, such as hairstyle, color and shape of eyes, color and texture of complexion [7-9].

Correspondence to: Tatjana Perović, DDS, Ph.D.

Sestre Baković 16/22, 18000 Niš, Serbia

Phone: +38118520763

E-mail: tatjana.tanic@gmail.com

Received May $14^{\text {th }}, 2019$ / Accepted May 29 $9^{\text {th }}, 2019$
What is the role of facial profile harmony in sagittal dentoskeletal pattern? Correlation between the facial profile harmony on the one hand and the sagittal dentoskeletal pattern and occlusal relationship on the other hand, has been the subject of research since the beginning of the last century, when Angle observed that the effect of sagittal malocclusion on facial contours produces different profile disharmonies. Angle also concluded that the profile balance quality would be proportional to the proximity with normal occlusion [3]. It has been established that Class I is more connected with a pleasant profile and Class III with the least evaluated profile aesthetics, which indicates that the sagittal position of the lower jaw affects the quality of profile aesthetics [10, 11]. However, Bittner et al [12] consider that there is no unconditional relationship between the profile harmony and the sagittal occlusal relationship, i.e. that occlusal deviations are only partially seen in the face. The occlusal relationship of Class II or III at the dental level basically does not have to be related to the skeletal disorder, while some subjects with Class I occlusion presented skeletal deviations adequately compensated by occlusion. Consequently, normal occlusion does not always indicate the profile harmony [12, 13].

The aim of this study has been to establish the values of soft tissue profile angles of facial convexity, facial convexity for the lower face and the overall angle of facial convexity in subjects with dentoskeletal Class I, Class II Division 1, Class II Division 2, and Class III 
pattern, in order to, in this way, examine the influence of sagittal dentoskeletal relation on the value of angular profile parameters, as well as to examine the significance of established differences for each angle separately.

\section{Material and Method}

The study was conducted at the Dental Clinic in Nis. Before the commencement of the study, each volunteer gave an informed consent as to the purpose and nature of the study. All work was performed in accordance with the Declaration of Helsinki and was approved by the Faculty's Ethics Committee, (General project title of Clinical and Experimental Examination of the Stomatognathic System and ModernTherapeutic Procedures, Project Number 11, of March 8, 2017, Nis, Republic of Serbia).

This study included the examination and the analysis of cephalometric radiography derived lateral cephalograms to evaluate profile angles for 120 adult Caucasian subjects (60 female and 60 male) from the mid-Balkan region (Serbia), which were taken from the patient archives. Cephalometric radiography derived lateral cephalograms were recorded during routine diagnostic procedures for patients who were examined at the Department of Jaw Orthopedics at the Clinic of Dentistry in Niš, aged between 18-30 years, and who underwent orthodontic therapy for the first time. Patients were excluded from the study if they had a history of trauma, craniofacial anomalies, cleft lip and palate, and previous orthodontic, prosthetic or orthognathic surgical treatment. Cephalometric radiographs of the head were done using a cephalostat (head-holding device). All patients included in the study underwent a detailed clinical assessment and analyses of their dental and skeletal profiles, as well as soft tissue profiles on cephalometric radiography. The equipment used for the imaging analyses was the Rotograf Plus (20090 Buccinasco MI Italy) (Number and series: 00036045), and the CEI-OPX/105X-ray tube (CEI, Bologna), which had a protective filter $(2.5 \mathrm{~mm}$ a luminum - equivalent). Lateral cephalometric films were taken from a distance of $165 \mathrm{~cm}$ from the tube, using a cephalostat to ensure rigid head fixation. The patients were placed in the cephalostat in such a way that the sagittal plane of the head was at a $90^{\circ}$ angle to the path of the X-rays. The Frankfort horizontal plane (from the lower edge of foramen orbitale and upper rim of the external auditory canal) was parallel to the ground, the teeth were in central occlusion position, and the lips were in relaxed position. No correction for magnification factors was required, since all the radiographs were taken with the same equipment and the same proportions. Each cephalogram was fixed on the viewing box with the profile to the right, and the acetate tracing paper was fixed by tape at the top. The soft tissue and skeletal features were traced manually in a darkened room, using a $0.5 \mathrm{~mm}$ lead pencil. All the image tracing was done by the main investigator. Subjects were divided into four groups. The criteria for categorizing into four groups in the study was the size of the ANB angle according to Steiner and the angle inclination of the upper incisors. The cephalometric ANB angle was the parameter that defined the sagittal relationship between the upper and lower jaw as orthognathic, distal, or mesial (Fig. 1). The points that determined the ANB angle included, point $(\mathrm{N})$, the nasion, located on the suture between the frontal and nasal bones; point $\mathrm{A}$, the lowest point on the line between the anterior nasal spine and the prosthion (alveolar point); and point B, the lowest point from the line between the infradentale and the pogonion (midline of the chin).

The first group was with an orthognathic jaw relationship (Class I) and the ANB angle between 2-4 ${ }^{\circ}$. The second group was with a distal jaw relationship, an ANB angle $>4^{\circ}$, and the inclination angle of the upper incisor $>22^{\circ}$ (Class II, Division I, or Class II/1). The third group was with a distal jaw relationship, an ANB angle $>4^{\circ}$ and the inclination angle of the upper incisors inclination $<22^{\circ}$ (Class II, Division 2, or Class II/2). The fourth group consisted of a mesial jaw relationship and an ANB angle $<1^{\circ}$ (Class III). Each group consisted of 30 subjects ( 15 female, 15 male). Since subjects with Class I generally show a harmonic profile due to the orthognatic jaw relationship, this group is taken as a control and compared to the other three groups.

Then, on the radiograph of each patient, the following anthropometric soft tissue points were determined (Table 1, Fig. 2)

By pulling lines from these points, the following profile angles have been formed (Fig. 3):

1. Facial convexity angle, excluding the nose (G-Sn$\mathrm{Pg}$ ) - angle between glabella to subnasale ( $\mathrm{Sn})$ line and subnasale $(\mathrm{Sn})$ to pogonion $(\mathrm{Pg})$ line;

2. Facial convexity angle for the lower profile part (G-Sn-Pg/1) - angle between glabella to subnasale (Sn) line and subnasale $(\mathrm{Sn})$ to pogonion $(\mathrm{Pg})$ line (supplementary angle to the previous angle);

3. Total facial convexity angle including the nose (G-Prn-Pg) - angle between glabela $(\mathrm{G})$ to pronasale (Prn) and pronasale (Prn) to pogonion (Pg) line.

Since these are angular measures, all results are expressed in degrees $\left({ }^{\circ}\right)$.

\section{Statistical analysis}

Statistical analysis of obtained morphometric data was performed by IBM SPSS Statistics (version 25). Results of the Kolmogorov-Smirnov test showed that majority of the morphometric parameters were not normally distributed. Consequently, significance of detected differences were evaluated by non-parametric Mann-Whitney $\mathrm{U}$ test. In the statistical evaluation, the following levels of significance were used: Not significant $p>0.05$; Significant $0.05 \geq \mathrm{p}>0.01(*)$; Highly significant $0.01 \geq \mathrm{p}>$ $0.001(* *)$; Very highly significant $\mathrm{p} \leq 0.001(* * *) ; \mathrm{p}=$ probability value. 


\section{Results}

Descriptive statistics of the average angular measurements for different parameters in all four groups with different jaw relationship (Class I, Class II/1, Class II/2,
Class III) are shown in Table 2. In the Table 3, statistical differences of average values of the examined angles between the group with Class I and the other three groups are shown.

Table 1 Facial landmarks used for the determination of angular parameters.

\begin{tabular}{ll}
\hline Glabella $(\mathrm{G})$ & the most anterior point of the middle line of the forehead \\
Subnasale $(\mathrm{Sn})$ & the point where the upper lip joins the columella \\
Pronasale $(\mathrm{Prn})$ & the most prominent point of the tip of the nose \\
Pogonion $(\mathrm{Pg})$ & the most anterior point of the chin
\end{tabular}

Table 2 Descriptive statistics for Class I, Class II division 1, Class II division 2 and Class III (mean value, standard deviation and min-max value).

\begin{tabular}{lrrrr}
\hline Classes & \multicolumn{1}{c}{ I } & \multicolumn{1}{c}{ II/1 } & \multicolumn{1}{c}{ II/2 } & \multicolumn{1}{c}{ III } \\
\hline G-Sn-Pg & $166.23 \pm 4.58$ & $159.30 \pm 6.23$ & $163.00 \pm 7.56$ & $174.13 \pm 6.42$ \\
Min-max & $158.0-174.0$ & $139.0-167.0$ & $151.0-182.0$ & $165.0-189.0$ \\
G-Sn-Pg/1 & $13.77 \pm 4.58$ & $20.70 \pm 6.23$ & $17.00 \pm 7.56$ & $5.87 \pm 6.42$ \\
Min-max & $6.0-22.0$ & $13.0-41.0$ & $-2.00-29.00$ & $-9.0-15.0$ \\
G-Prn-Pg & $141.17 \pm 5.02$ & $136.30 \pm 6.24$ & $137.43 \pm 5.33$ & $144.57 \pm 6.62$ \\
Min-max & $129.0-150.0$ & $121.0-147.0$ & $127.0-145.0$ & $131.0-160.0$ \\
\hline
\end{tabular}

Table 3 Statistical differences between Class I and other groups ( $\mathrm{Z}$ value; $\mathrm{p}$ - probability value).

\begin{tabular}{llrrrr}
\hline Classes & & $\mathrm{I}-\mathrm{II} / 1$ & $\mathrm{I}-\mathrm{II} / 2$ & $\mathrm{I}-\mathrm{III}$ \\
\hline $\mathrm{G}-\mathrm{Sn}-\mathrm{Pg}$ & $(\mathrm{Z})$ & & -4.167 & -2.555 & -4.564 \\
& & $\mathrm{p}$ & $<0.001^{* * *}$ & $0.011^{* * *}$ & $<0.001^{* * * *}$ \\
$\mathrm{G}-\mathrm{Sn}-\mathrm{Pg} / 1(\mathrm{Z})$ & & -4.167 & -2.555 & -4.564 \\
& & $\mathrm{p}$ & $<0.001^{* * *}$ & $0.011^{* *}$ & $<0.001^{* * *}$ \\
G-Prn-Pg & $(\mathrm{Z})$ & & -3.030 & -2.681 & -1.831 \\
& & $\mathrm{p}$ & $0.002^{* *}$ & $0.007^{* *}$ & 0.067 \\
\hline
\end{tabular}

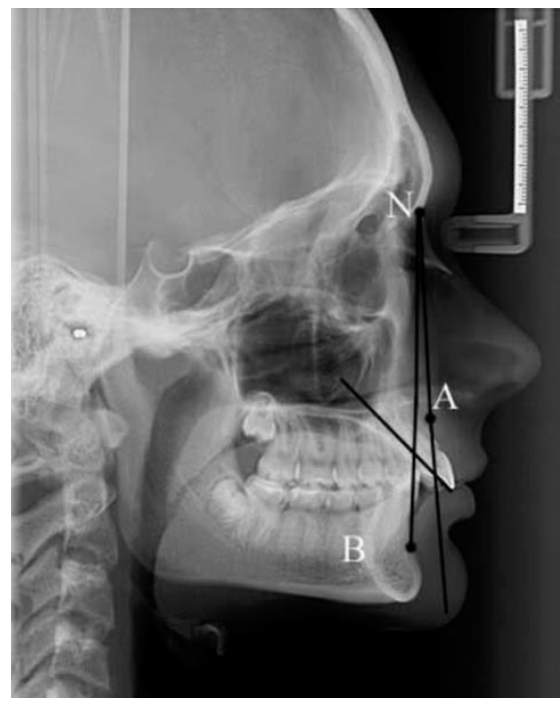

Fig. 1 The cephalometric ANB angle and the angle of inclination of upper incisors.

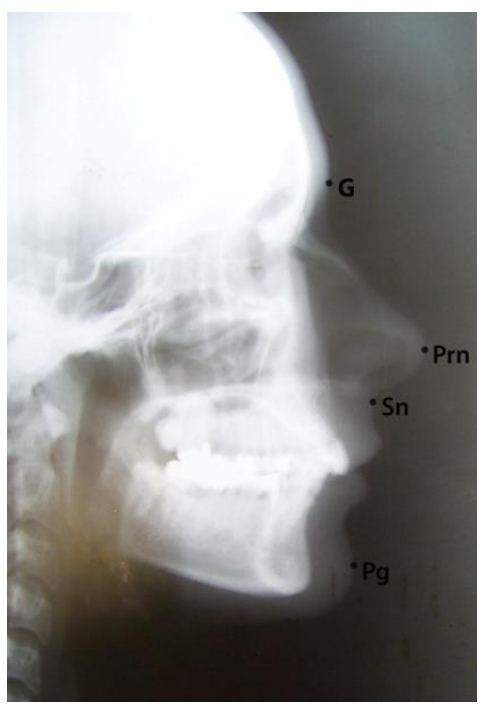

Fig. 2 The landmarks used in this investigation: glabella $(\mathrm{G})$, pronasale (Prn), subnasale $(\mathrm{Sn})$, pogonion $(\mathrm{Pg})$.

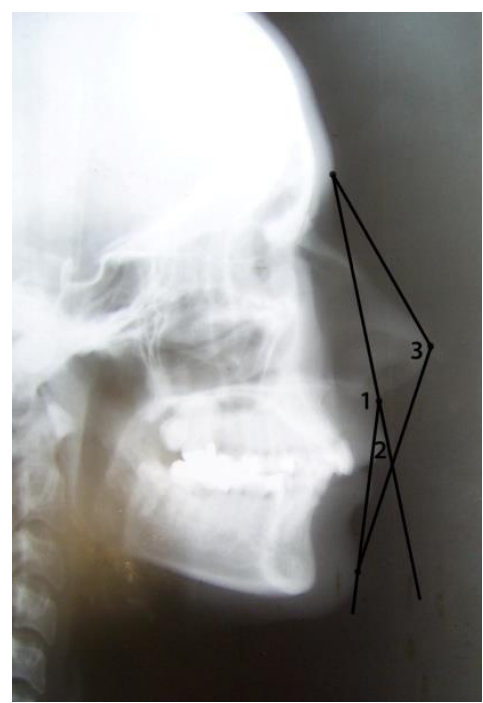

Fig. 3 Angular parameters: 1. the facial convexity angle (excluding the nose) (G-Sn-Pg); 2. the facial convexity angle for lower part of facial profile $(\mathrm{G}-\mathrm{Sn}-\mathrm{Pg} / 1)$; 3. total facial convexity angle (including the nose) (G-Prn-Pg). 


\section{Discussion}

The development of the facial soft tissue profile is the result of complex changes in the facial hard and soft tissue structures [14]. Altemus found a high variability in the thickness of soft tissue of some profile segments [15]. This was confirmed by subsequent researches of this topic [16-21]. Although the skeletal profile is inclined to "correction" during maturation, the soft tissue profile has remained relatively convex, with convexity decreasing with the age growth [22-24].

The established average values of the facial convexity angle for Caucasian subjects with a class amount to (according to different authors): $168.8 \pm 4.96^{\circ}$ [5], $168 \pm 6^{\circ}$ [10], $169.4 \pm 3.2^{\circ}[20]$, and according to the current study, $166.23 \pm 4.58^{\circ}$, that is somewhat lower than the quoted ones. For subjects with Class II, the values are significantly lower - $159.30 \pm 6.23(\mathrm{p}<0.001)$ for Division $1 ; 163.00 \pm$ $7.56^{\circ}(p=0.011)$ for Division 2. Contrary to the previous one, for subjects with Class III, the average value of this angle is $174.13 \pm 6.42(\mathrm{p}<0.001)$ (Table 2, 3). A similar result was obtained by Godt et al [25] with significant differences of this angle between the subjects with a different dentoskeletal pattern, as expected, because the undeveloped mandible in Class II is positioned more Pogonion posterior while overdeveloped in Class III is positioned more anterior than in Class I. Other studies of the influence of sagittal jaw relationship to the profile harmony confirm that the facial convexity angle is extremely sensitive to sagittal skeletal disorders $[5,10,26]$. Fortes et al [26] by comparing the values of this angle in the Caucasion Brazilian subjects with a pleasant and unpleasant facial profile, established an average of $169.20 \pm 3.88^{\circ}$ for a pleasant facial profile and $165.17 \pm 5.81^{\circ}$ for unpleasant facial profiles, which implicitly points out that the reduction of this angle affects the aesthetic perception in a negative way. The difference is statistically significant.

The facial convexity angle for the lower face represents the supplementary angle to the previous one and allows an estimation of the chin projection in relation to the middle part of the face.According to Reis et al [10] its normal value is $12.32 \pm 3.93^{\circ}$, and according to Uysal et al [27] it is $14.2^{\circ}$ for women and $12.1^{\circ}$ for men. When comparing the value of facial convexity angle of the lower face, the significance finding is identical to the previous angle $(\mathrm{G}-$ $\mathrm{Sn}-\mathrm{Pg}$ ), with the average value for subjects with Class II/1 $(20.7 \pm 6.23)$ and Class II/2 $\left(17 \pm 7.56^{\circ}\right)$ is higher while for subjects with Class III $\left(5.87 \pm 6.42^{\circ}\right)$ it is lower compared to subjects with Class I $\left(13.77 \pm 4.58^{\circ}\right)$ (Table 2). Similar findings were published by other authors [10, 28, 29]. According to these studies, people whose facial convex angles are above $16.25^{\circ}$ or below $8.39^{\circ}$ have an aesthetically disharmonic profile.

Furthermore, there is a direct connection between the profile convexity and an unpleasant aesthetic profile [10]. For a female profile, the recommended type is slightly convex, while for a male profile, the advantage is given to the straight profile. Any increase of this angle above standard deviation of the average harmonic profile was associated with a reduced result of profile aesthetics. It is believed that women with increased and men with reduced anterior chin projection are less attractive [30, 31].

For the values of total facial convexity angle (G-Prn$\mathrm{Pg}$ ), for the group of our subjects with dentoskeletal Class I pattern, average values of $141.17 \pm 5.02^{\circ}$ have been determined (Table 2). This is close to the values established for the Croatian population $141.55 \pm 4.074^{\circ}$ [5], but the values of this angle do not differ much with other researchers: Wen et al [4] $141.5^{\circ}$ for men and $141.0^{\circ}$ for women; Panadian et al [13] determined $141.54 \pm 4.96$ for men and $140.92 \pm 4.79$ o for women.

By comparing differences of average values between groups, significant differences have been established between Class I and II/1 $\left(136.30 \pm 6.24^{\circ} ; \mathrm{p}=0.002\right)$, Class I and II $/ 2\left(137.43 \pm 5.33^{\circ} ; p=0.007\right)$. Differences in values between Class I and III have not shown any significance (Table 3).

Fortes et al [26] compared this angle with Caucasian Brazilian subjects with a pleasant and unpleasant facial profile and set a value of $142.67 \pm 4.72^{\circ}$ for pleasant facial profiles and $139.10 \pm 4.95^{\circ}$ for unpleasant facial profiles. The difference is statistically significant. It is interesting that the published papers examining this problem pointed to the fact that the total facial convexity angle, with nasal projection taken into account is not related to profile aesthetics. What might the explanation be? The facial convexity angle is directly related to the sagittal jaw relationship, i.e. to the sagittal pattern, and therefore any changes in its value are directly related to the sagittal deviations between jaws. The total facial convexity angle, however, gives an estimation of the nasal projection in relation to the chin and forehead. The change in this convexity type can be associated not only with skeletal disagreements but also with higher or smaller nasal projection, that does not similarly affect the aesthetic profile estimate [32].

However, some researchers think otherwise - the main factors responsible for the unpleasant profile aesthetics were the nose in $38.35 \%$ of cases and chin in $18.9 \%$ of cases $[10,33]$.

\section{Conclusion}

By investigating the influence of the sagittal dentoskeletal pattern on the value of facial convexity angles, significant differences have been established between subjects with Class I and Class II Division 1 and 2 for all examined angles, while the differences between Class I and Class III are only significant for the facial convexity angle and facial convexity angle for the lower face, while the differences in the total facial convexity angle are not significant. 


\section{References}

1. Frith C. Role of facial expressions in social interactions. Philos Trans R Soc Lond B Biol Sci 2009; 364:3453-3458.

2. Heppt WJ, Vent J. The facial profile in the context of facial aesthetics. Facial Plast Surg 2015; 31(5):421-430.

3. Peck H, Peck S. A concept of facial esthetics. Angle Orthod 1970; 40(4):284-318

4. Wen YF, Wong HM, Lin R, Yin G, McGrath C. Inter-ethnic/racial facial variations: a systematic review and Bayesian meta-analysis of photogrammetric studies. PLoS ONE 2015; 10(8):e0134525.

5. Anić-Milošević S, Lapter-Varga M, Šlaj M. Analysis of the soft tissue facial profile by means of angular measurements. Eur $\mathbf{J}$ Orthod 2008; 30(2):135-140.

6. Diomande M, Beugre JB, Koueita MKK, Vaysse F. Relationship between angular measurements and facial shape of young Ivorians with normal dental occlusion. Scientific World Journal 2018: 6395910

7. Al Taki A, Guidoum A. Facial profile preferences, self-awareness and perception among groups of people in the United Arab Emirates. J Orthod Sci 2014; 3(2):55-61.

8. Sundareswaran S, Ramakrishnan R. The Facial Aesthetic index: An additional tool for assessing treatment need. J Orthod Sci 2016; 5(2):57-63.

9. Spyropoulos MN, Halazonetis DJ. Significance of the soft tissue profile on facial esthetics. Am J Orthod Dentofacial Orthop 2001; 119(5):464-471.

10. Reis SAB, Abrão J, de Assis Claro CA, CapelozzaFilho L. Evaluation of the determinants of facial profile aesthetics. Dental Press J Orthod 2011; 16(1):57-67.

11. Dongieux J, Sassouni V. The contribution of mandibular positioned variation to facial esthetics. Angle Orthod 1980;50(4):334-339.

12. Bittner C, Pancherz H. Facial morphology and malocclusions. Am J Orthod Dentofacial Orthop 1990: 97(4):308-315.

13. Pandian KS, Krishnan S, Kumar SA. Angular photogrammetric analysis of the soft-tissue facial profile of Indian adults. Indian $\mathbf{J}$ Dent Res 2018; 29(2):137-343.

14. Neslihan SC. Comparisons of Soft Tissue Thickness Measurements in Adult Patients With Various Vertical Patterns. Meandros Med Dent J 2017; 18:120-129.

15. Altemus LA. Comparative integumental relationships. Angle Ortodontist 1963; 33(3):217-221.

16. Perović T, Blažej Z. Male and female characteristics of facial soft tissue thickness in different orthodontic malocclusions evaluated by cephalometric radiography. Med Sci Monit 2018;24:3415-3424.

17. Hamid S, Abuaffan A. Facial soft tissue thickness in a sample of Sudanese adults with different occlusions. Forensic Sci Int 2016; 1266:209-214.

18. Ramesh G, Nagarajappa R, Sreedhar G, Sumalatha MN. Facial Soft Tissue Thickness in Forensic Facial Reconstruction: Is it enough if Norms Set? J Forensic Res 2015;6(5):1000299.
19. Somaiah S, Khan MU, Muddaiah S, Shetty B, Reddy G, Siddegowda R. Comparison of soft tissue chin thickness in adult patients with various mandibular divergence patterns in Kodava population. Int J Orthod Rehabil 2017; 8(2):51-56.

20. Jabbar A, Zia A, Shaikh I, Channar K, Memon A, Jatoi N. Evaluation of soft tissue chin thickness in various skeletal malocclusions. Pakistan Orthodontic Journal 2016;8(1):62-66.

21. Tanić T, Blažej Z, Mitić V. [Soft tissue thickness of face profile conditioning by dento-skeletal anomalies.] Srp Arh Celok Lek 2011; 139(7-8):439-445. (Serbian, English abstract)

22. Obaidi HA, Abdul-Qadir MY. Facial soft tissue convexity changes. Al-Rafidain Dent J 2007; 7(1):88-95.

23. Prahl-Andersen B, Ligthelm-Bakker ASWMR, Wattel E, Nanda K. Adolescent growth changes in soft tissue profile. Am J Orthod Dentofac Orthop 1995; 107(5):476-483.

24. Bishara SE, Jackobsen JR, Hession TJ, Treder JE. Soft tissue profile changes from 5-45 years of age. Am J Orthod Dentofac Orthop 1998; 114(6):698-706

25. Godt A, Müller A, Kalwitzki M, Göz G. Angles of facial convexity in different skeletal Classes. Eur J Orthod 2007;29(6):648-53.

26. Fortes HN, Guimarães TC, Belo IM, Matta EN. Photometric analysis of esthetically pleasant and unpleasant facial profile. Dental Press J Orthod 2014; 19(2):66-75.

27. Uysal T, Baysal A, Yagci A, Sigler LM, McNamara JA Jr. Ethnic differences in the soft tissue profiles of Turkish and EuropeanAmerican young adults with normal occlusions and well-balanced faces. Eur J Orthod 2012; 34(3):296-301.

28. Reis SAB, Abrão J, CapelozzaFilho L, Claro CAA. [Estudocomparativo do perfil facial dos Padrões I, II e III portadores de selamento labial passive.] Rev Dental Press Ortod Ortop Facial 2006;11(4):36-45. (Portuguese, English abstract)

29. Reis SAB, Abrão J, CapelozzaFilho L, Claro CAA. [Análise facial numérica do perfil de brasileirosPadrão I.] Rev Dental Press Ortod Ortop Facial 2006; 11(6):24-34. (Portuguese, English abstract)

30. Czarnecki ST, Nanda RS, Currier GF. Perceptions of a balanced facial profile. Am J Orthod Dentofacial Orthop 1993; 104(2):180-187.

31. Ioi H, Nakata S, Nakasima A, Counts A. Effect of facial convexity on antero-posterior lip positions of the most favored Japanese facial profiles. Angle Orthodontist 2005;75(3):326-332.

32. Fernández-Riveiro $\mathrm{P}$, Smyth-Chamosa E, Suárez-Quintanilla D, Suárez-Cunqueiro M. Angular photogrammetric analysis of the soft tissue facial profile. Eur J Orthod 2003; 25(4):393-399.

33. Auger TA, Turley PK. The female soft tissue profile as presented in fashion magazines during the 1900s: a photographic analysis. Int J Adult Orthodon Orthognath Surg 1999; 14(1):7-18 